\title{
Status of TIGA activities at the British Isles continuous GNSS Facility and the University of Luxembourg
}

\author{
A. Hunegnaw - F. N. Teferle - R. M. Bingley · D. N. Hansen
}

Received: date / Accepted: date

\begin{abstract}
In 2013 the International GNSS Service (IGS) Tide Gauge Benchmark Monitoring (TIGA) Working Group started their reprocessing campaign which proposes to reanalyse all relevant GPS observations from 1995 to the end of 2012 in order to provide high quality estimates of vertical land motion for monitoring of sea level changes. The TIGA Working Group will also produce a combined solution from the individual TIGA Analysis Centres (TAC) contributions. The consortium of British Isles continuous GNSS Facility (BIGF) and the University of Luxembourg TAC (BLT) will contribute weekly minimally constrained SINEX solutions from its reprocessing using the Bernese GNSS Software (BSW) version 5.2 and the University of Luxembourg will also act as a TIGA Combination Centre (TCC). The BLT will generate two solutions, one based on BSW5.2 using a network double difference (DD) strategy and a second one based on BSW5.2 using a Precise Point Positioning (PPP) strategy. In the DD strategy we have included all IGb08 core stations in order to achieve a consistent reference frame implementation.

As an initial test for the TIGA combination, all TACs agreed to provide weekly SINEX solutions for a four-week period in December 2011. Taking these individual TAC solutions the TCC has computed a first combination using two independent combination software packages: CATREF and
\end{abstract}

A. Hunegnaw, F. N. Teferle

Faculté des Science, de la Technologie et de la Communication, University of Luxembourg, 6 rue Richard Coudenhove-Kalergi L-1359, Luxembourg

E-mail: addisu.hunegnaw@uni.lu

R. M. Bingley, D. N. Hansen

Nottingham Geospatial Institute, University of Nottingham, NG7 2TU Nottingham, UK
GLOBK. In this study we will present preliminary results from the BLT reprocessing and from the combination tests.

Keywords TIGA · Reprocessing · Combination · SINEX · GPS

\section{Introduction}

Sea level change as a consequence of climate variations has a direct and significant impact for coastal areas around the world. Over the last two centuries sea level changes have been estimated from the analysis of tide gauge records. However, tide gauges measure sea level relative to benchmarks on land. It is well established that these records need to be de-coupled from vertical land movements. Global Navigation Satellite System (GNSS) technology, in particular the Global Positioning System (GPS), has made it possible to obtain highly accurate measurements of vertical land movements close to or at tide gauges (Teferle et al., 2006; Wöppelmann et al., 2007; Rudenko et al., 2013).

Under the umbrella of the International GNSS Service (IGS), the Tide Gauge Benchmark Monitoring (TIGA) Working Group has been established to bring expertise of the GNSS community to solve issues related to the accuracy and reliability of the vertical component as measured by GPS and to provide time series of vertical land movement in a well-defined global reference frame (Schöne et al., 2009). In the past, to achieve this objective up to six TIGA Analysis Centres (TACs) were contributing individual solutions, employing different GPS processing software and analysis strategies. Some of the TACs have carried out their processing based on old IGS standards such as relative satellite and receiver antenna phase centre variation (PCV) models. In effect, interpreting GPS-derived vertical land movements will be difficult due to inconsistencies caused by model and strategy differences. This gave the motivation for the TIGA 
working group to start a reprocessing campaign which proposes to re-analyse all relevant GPS observations from 1995 to the end of 2012, conforming to the latest IGS standards.

The consortium of the British Isles continuous GNSS Facility (BIGF) and the University of Luxembourg TIGA Analysis Centres (BLT), as one of the TIGA Analysis Centres (TAC), has started a reprocessing of more or less the complete TIGA archive hosted at the University of La Rochelle (ULR). The BLT will generate SINEX format solutions based on the Bernese GNSS Software (BSW) version 5.2 (Dach et al., 2007), one using a network double difference (DD), and the second a Precise Point Positioning (PPP) strategy. Internally BLT will generate two network DD solutions, one at BIGF and one at the University of Luxembourg (UL), which only differ in their station selection. Only one internally combined SINEX file will be delivered to the TIGA working group.

In the past, the networks processed by the individual TACs differed significantly, some were regional and some were global with very few or none common stations between them (Schöne et al., 2009). The quality of a combined solution depends on the number of common stations in the contributing TAC solutions, which can be used during the combination. Currently, there are three global TACs solutions available with varying numbers of common stations between them.

In order to improve the redundancy in our preliminary combination test, we have included the solution from IGS Analysis Centre (AC) at the Massachusetts Institute of Technology (MIT). Table 1 lists the three TACs (BLT, GFZ, ULR ) and one IGS AC (MIT) contributing to this combination test. All the three TACs include a core global network list of sites from IGb08 reference stations (Rebischung, 2012). Taking these individual TAC solutions, the TCC has computed a first combination using two independent combination software packages: Combination and Analysis of Terrestrial Reference Frame (CATREF) (Altamimi et al.., 2002) and Global Kalman filter VLBI and GPS analysis program (GLOBK) (Herring and King, 2006).

In this study we will present preliminary results from the BLT reprocessing, a comparison of two independent combinations using software packages CATREF and GLOBK, and a first TIGA combination for a test period in December 2011.

\section{Processing and Combination Methodologies}

The BLT reprocessing strategy follows closely that of (Steigenbe 2006) while incorporating recent model developments and the latest International Earth Rotation and Reference Systems Service (IERS) 2010 conventions (Petit and Luzum, 2010). We summarize our network DD processing in Table 2. The
Table 1 TIGA and IGS Analysis Centres used in this study

\begin{tabular}{ll}
\hline TAC(AC) & Description \\
\hline ULR & Centre Littoral de Geophysique, University of \\
& La Rochelle (ULR), France \\
GFZ & GeoForschungsZentrum Potsdam (GFZ), Germany \\
BLT & British Isles continuous GNSS Facility and \\
& the University of Luxembourg TAC (BLT), UK and \\
& Luxembourg \\
MIT & Massachusetts Institute of Technology, USA \\
\hline
\end{tabular}

two BLT partners each process all IGb08 core stations. Additionally, BIGF includes the dense network of the British Isles while the UL covers more or less the complete archive of TIGA ${ }^{1}$ (see Figure 1). Hence UL generates daily SINEX solutions from up to 450 GPS stations using the UL High Performance Computing (HPC) facility. The daily free normal equations from both BLT partners are combined for computing a minimum constrained solution (no-net rotation and no-net translation) conditions with respect to the IGb08 reference frame. Stations with large residuals exceeding $\pm 20 \mathrm{~mm}$ in the North and East components, and $\pm 30 \mathrm{~mm}$ in the Up component in the daily combination are reduced from the normal equations.

Independent of the BLT TIGA solution, UL has also produced a PPP solution from 1995 to the end of 2012. Firstly, this serves as an internal quality control of the TIGA archive held at the University of La Rochelle (ULR) and the information held by BLT. This highlighted a number of issues related to non-IGS station log files and respective RINEX header information. Secondly, PPP provides good quality a priori coordinate solutions for non-IGS stations.

The PPP strategy is made possible by fixing Centre for Orbit Determination in Europe (CODE) final satellite orbits, satellite clocks and Earth rotation parameters (ERP). This processing follows more or less the description in Table 2.

However, our final reprocessed solution will be based on the network DD strategy along with other TACs SINEX files to generate a combined SINEX file.

As part of the TIGA reprocessing, all TACs will provide minimally-constrained solutions in the form of SINEX files for the TIGA combination. It was agreed that all TACs would provide four weeks of SINEX solutions for the GPS weeks 1665-1668, i.e. December 2011. So far, only three TAC solutions have become available for the combination test (see Figure 2) but at least one more is expected to be available for the final combination. The main purpose of the combination is to determine better coordinate estimates for all TIGA stations expressed in the current IGb08 refreceteshame. Prior to combination the TACs solutions are pre-processed and checked for completeness and conformity of their SINEX files and for station name inconsistencies.

\footnotetext{
1 http://tiga.sonel.org/
} 
Table 2 Summary of the GPS data processing strategy at the UL

\begin{tabular}{|c|c|}
\hline Paramters & Description \\
\hline GPS software & Bernese Version 5.2 (Dach et al., 2007) \\
\hline Data & Double-differenced phase and code observations from up to 450 stations per day \\
\hline Elevation cut-off angle & $3^{o}$ and elevation dependent weighting $\left(w=\cos ^{2} z\right.$, zenith angle $\left.z\right)$ \\
\hline Ionospheric refraction & Ionospheric-free linear combination (L3) \\
\hline Tropospheric refraction & $\begin{array}{l}\text { An a priori dry tropospheric delay (Saastamoinen) computed from standard atmosphere. For wet part continuous } \\
\text { piecewise-linear troposphere parameters estimated in } 2 \text {-hour interval, plus gradients in } \\
\text { north-south and east-west directions at } 24 \mathrm{~h} \text { intervals. }\end{array}$ \\
\hline Earth orientation & C04 series IERS Bulletin B \\
\hline Antenna PCV & $\begin{array}{l}\text { IGS absolute elevation and azimuth dependent PCV igs08.atx file } \\
\text { (http://igscb.jpl.nasa.gov/igscb/station/general/pcv_archive) }\end{array}$ \\
\hline Earth and polar tide & IERS2010 (Petit and Luzum, 2010) \\
\hline Ocean Loading & Computed using FES2004 ocean tide model (http://holt.oso.chalmers.se/loading/) \\
\hline Datum & $\begin{array}{l}\text { No-Net-Rotation (NNR) and No-Net-Translation (NNT) with respect to IGb08 (Rebischung, 2012). However, } \\
\text { any conditions such as NNT or No-Net-Scale (NNS) or a combination of them can be applied since } \\
\text { we save the normal equations of our DD processing }\end{array}$ \\
\hline Ambiguity Resolution & Resolved to integers up to $6000 \mathrm{~km}$ using different techniques depending on the baseline length \\
\hline Meta data & Intensive meta data check \\
\hline
\end{tabular}

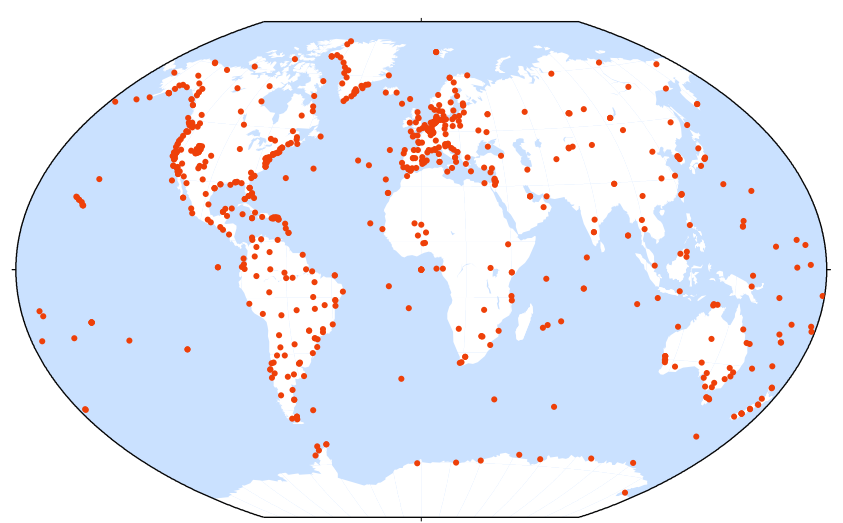

Fig. 1 GPS network processed at UL for TIGA.

Then the constraints applied to the individual solutions are removed and the normal equations of the parameter set of interest are added together. The reconstruction of the individual unconstrained normal equation system $\left(\mathbf{N}_{i}^{u n c}\right)$ provided by the TACs for consecutive weekly epoch $t$ is done using equation 1:

$\mathbf{N}_{i, t}^{u n c}=\hat{\sigma}_{i, t}^{2} \mathbf{C}_{\hat{\mathbf{x}}_{i, t} \hat{\mathbf{x}}_{i, t}}^{-1}-\hat{\sigma}_{i, t}^{2} \mathbf{C}_{\mathbf{x}_{i, t} \mathbf{x}_{i, t}}^{-1}$

where the variance-covariance matrix of the parameters $\left(\mathbf{C}_{\hat{\mathbf{x}} \hat{\mathbf{x}}}\right)$ computed from the constraints applied are provided in the form of a SINEX file. $\hat{\sigma}$ is the a posteriori variance factor. The resulting loose normal equation matrix should be singular, resulting from the three degrees of freedom of the unobserved network orientation. To remedy the rank deficiency and to define a uniform reference frame, constraints are imposed to estimate the final solution through LeastSquares and Kalman Filter procedure, as implemented in the CATREF and GLOBK approaches, respectively. Readers are referred to (Altamimi et al.., 2002) and (Dong et al.,

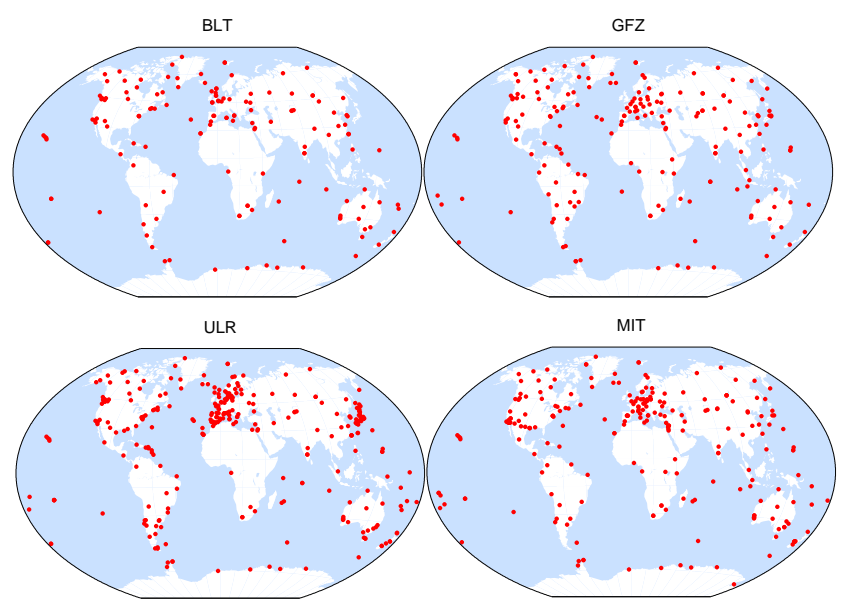

Fig. 2 TIGA (BLT, GFZ and ULR) and IGS (MIT) AC solutions used for the TIGA combination in this study

1998) for the general mathematical combination models used in CATREF and GLOBK, respectively.

\section{Results: BLT Processing and Assessment of Combinations using CATREF and GLOBK}

This section presents preliminary results of the BLT reprocessing, a comparison of CATREF and GLOBK combinations, and of the four-week TIGA combination test.

\subsection{Reprocessing}

Reprocessing following the final network DD strategy using BSW5.2 is well under way at both BLT consortium partners and the results will likely be available by the middle of 2014 . Here we only show a set of daily PPP and DD solutions for 
2011. Note, PPP only serves as a quality check and provides a priori coordinates for non-IGS stations. For example, Figure 3 compares the daily PPP and DD North, East and Up component time series for ONSA. Overall the time series from both processing solution agree well. As expected the weighted root mean square (WRMS) shows a significant improvement for the DD over the PPP solution, especially for the horizontal components. The largest improvement (34\%) is seen for the East component and stems largely from the ability of the DD strategy to resolve carrier-phase ambiguities to integers (Blewitt, 1989). This is not possible for PPP in BSW5.2, but it has been shown to result in a $30 \%$ improvement of the East component (Ge et al., 2008), which is clearly in agreement with this study. Although the PPP solution agrees well with the network DD one in all three components, there are some systematic differences between them. For example, at ONSA both the horizontal components (North and East) show short-term deviations (Figure 3 ). These may be a result of the satellite orbit and clock, as well as the Earth rotation products applied during processing or may stem from insufficient modelling of systematic biases which is of particular importance for PPP. Also the inconsistent use of these models during product generation and their application during processing by users has resulted in such (Fu et al., 2012). However, there is no discernible bias in the PPP solution in the Up component.
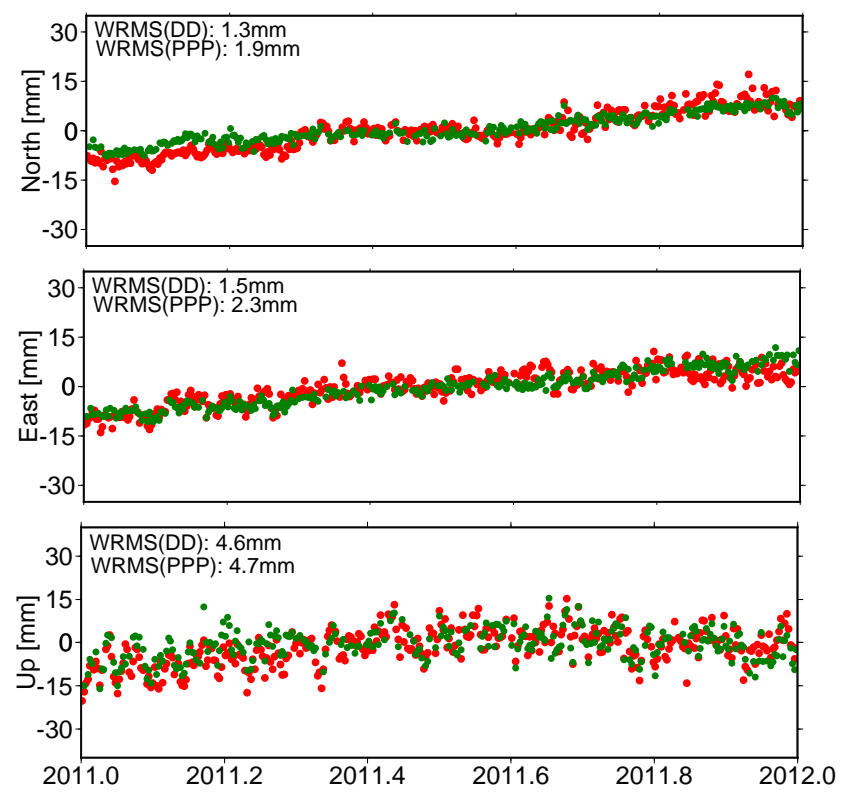

Fig. 3 Local topocentric components (East, North and Up) time series for station ONSA. Red circles represent the PPP, green the DD strategy. Also shown are the weighted root mean square (WRMS) statistics for PPP and DD solutions

\subsection{Assessment of Combinations using CATREF and GLOBK}

To assess the implementation of CATREF at TCC UL, we combined 8 IGS AC solutions. Each of these included different numbers of stations, ranging from 189 to 450 . A key aspect of the CATREF combination process is the selection of a realistic weight for each of the contributing ACs. For this, an a posteriori variance factor (scaling) is applied to all individual covariance matrices in an iterative way until both the individual and global variances are unity. Note that during this procedure outlier rejection is applied to those stations having a normalized position residual (raw residual divided by its observation a priori error) exceeding a threshold of five. In our case, three iterations were necessary to provide a refined estimation of variance factors free from the influence of outliers with respect to the threshold criteria.

We compare the individual transformation parameters of the eight IGS AC solutions that were used in our combination with the official IGS report section 5.3.1 for GPS week $1666^{1}$. The reported transformation parameters agree well, particularly in the translation parameters, not shown here.

Following our CATREF implementation, we have also generated an independent solution using the GLOBK software package by combining the same eight IGS AC solutions. The difference in the estimated Cartesian coordinates between the two packages is shown in Figure 4. In this figure the differences are ordered alphabetically according to the IGS station four-character ID. There are neither systematic variations nor a bias visible in the figure. We calculated RMS values of $0.5 \mathrm{~mm}, 0.5 \mathrm{~mm}$, and $0.6 \mathrm{~mm}$ for the $\mathrm{X}, \mathrm{Y}$ and $\mathrm{Z}$ component, respectively.

After rearranging the coordinate differences regionally according to the station nine-character DOMES number, we plotted them again, see Figure 5. We can now see clear systematic variations in the differences. Furthermore it is suggested that small biases between the combined solutions of the two software packages exist. For example, the coordinate differences between points 80 and 170 show those stations located in North America. If we only take their differences we find RMS values of $0.3 \mathrm{~mm}$ in all three components and biases of $0.3 \mathrm{~mm}$ in both $\mathrm{X}$ and $\mathrm{Y}$ components, and $0.5 \mathrm{~mm}$ in the $\mathrm{Z}$ component. Although these sub-millimetre coordinate differences may be negligible, their impact should be further investigated based on multi-year combination results.

This study confirms that the two independent combinations as implemented by the TCC at UL agree at the one millimetre level and demonstrates that either of the two independent software packages may be used by the TCC. However, there is a significant advantage of GLOBK over CATREF in terms of processing time.

\footnotetext{
${ }^{1}$ http://igscb.jpl.nasa.gov/pipermail/igsreport/
} 


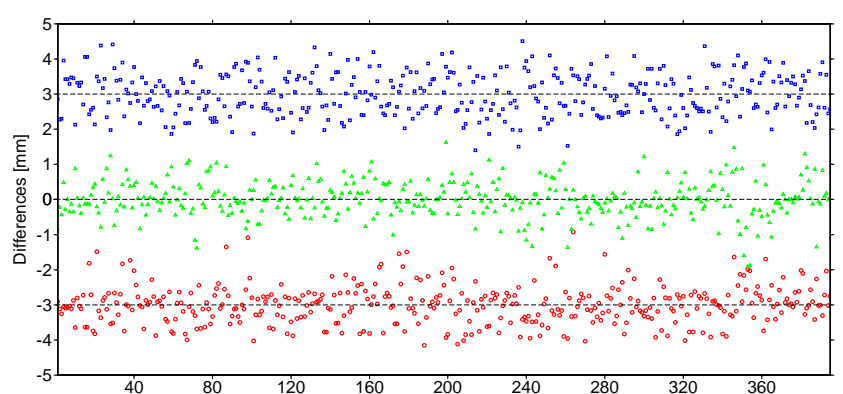

Fig. 4 Coordinate differences for 400 stations between CATREF/GLOBK combination of eight IGS AC solutions for December 2011. The differences are arranged alphabetically according to the IGS station four-character ID. Green circles represent the coordinate differences for the $\mathrm{X}$, red for the $\mathrm{Y}$ and blue for the $\mathrm{Z}$ component. For clarity the $\mathrm{Y}$ and $\mathrm{Z}$ components are offset by $3 \mathrm{~mm}$.

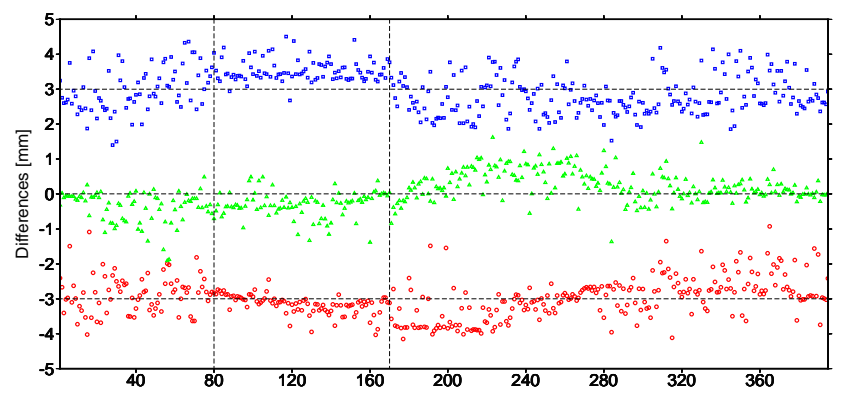

Fig. 5 Coordinate differences for 400 stations between CATREF/GLOBK combination of eight IGS AC solutions for December 2011. The differences are arranged regionally according to the station nine-character DOMES number. For example, the coordinate differences between points 80 and 170 (the two vertical dotted lines) show those stations located in North America. Green circles represent the coordinates differences for the $\mathrm{X}$, red for the $\mathrm{Y}$ and blue for the $\mathrm{Z}$ component. For clarity the $\mathrm{Y}$ and $\mathrm{Z}$ components are offset by $3 \mathrm{~mm}$.

\subsection{Results: TIGA combination}

We present the results of the TIGA combination using three TACs solution and the solution from the IGS AC at MIT for GPS Weeks 1665-1668. Figure 6 shows the number of common stations available for this test period in December 2011. This figure indicates that there are more overlapping stations between the TACs compared to previous TIGA solutions (Schöne et al., 2009). One of the requirements for TIGA reprocessing is that TACs include all IGb08 core stations.

Figure 7 depicts the Helmert transformation parameters between the individual TAC and the combined solutions. The error bars plotted in this Figure are 1-sigma standard errors of the Helmert transformation parameters. The transformation parameters are indicative of the influence of each individual solution on the combined solution and thus traditionally are used as precision indicators for the combined solution. Except for the $\mathrm{Z}$ translation parameter from ULR,

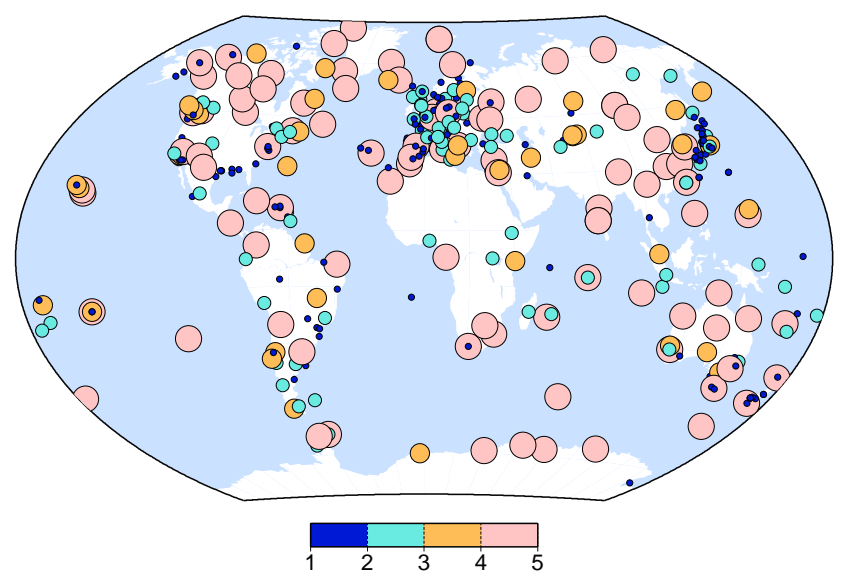

Fig. 6 The number of TACs per site for the GPS week 1666 combination.
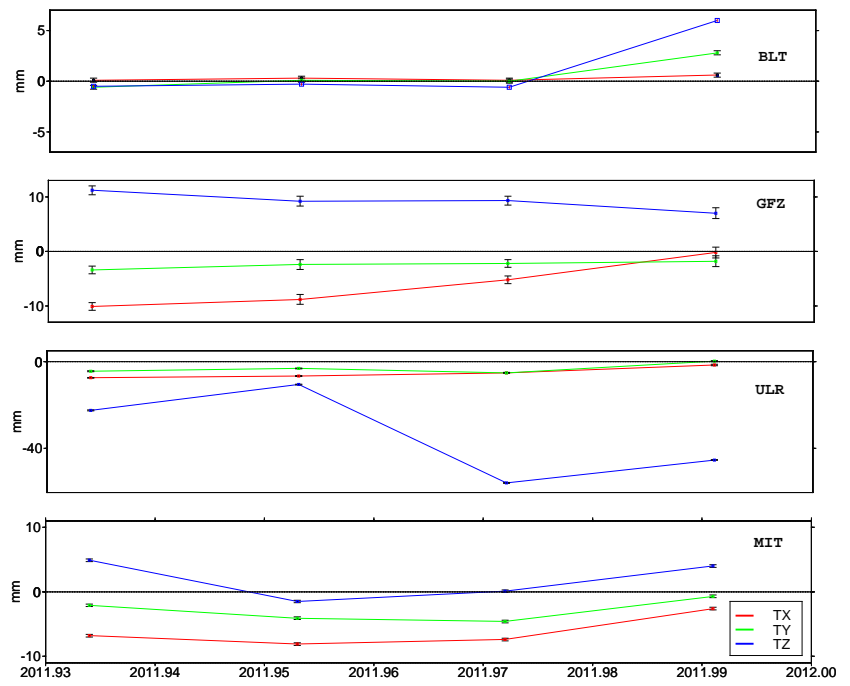

Fig. 7 Translation parameters time series between BLT, GFZ, ULR and MIT solutions and the combined solution for the test period in December 2011 with error bars. The X-axis is in decimal year that corresponds to the GPS week.

the results show consistency of the individual solution on a weekly basis. The inconsistency in ULR's Z translation parameter may stem from their dynamic station selection, which changes on a daily basis (Wöppelmann et al., 2009). However, it is difficult to draw any firm conclusions based on only a four-week test period. We note that the TIGA combination is particularly beneficial compared to the IGS combination for sea level studies. This is because the TAC SINEX files contain non-IGS GPS stations that are near or at tide gauge as well as many of the South America sites compared to the IGS AC SINEX files. 


\section{Conclusions}

In this study we have presented preliminary results from the BLT reprocessing, a comparison of two independent combinations using software packages CATREF and GLOBK, and a first TIGA combination for December 2011. Attempting to exploit the complete TIGA archive, an initial processing using PPP has identified series issues with non-IGS station $\log$ files that restricted recovering important components of station information. After resolving these and inconsistencies between station log files and RINEX header information, accurate a priori coordinates for non-IGS stations were estimated.

The comparison of the two combination software packages revealed millimetre-level agreement in the coordinates of 400 stations. However, the coordinate differences exhibit regionality, with regional variations in scatter and biases. An issue that requires further investigation for long-term combinations.

Our study has generated a preliminary TIGA combination from three TAC solutions for December 2011. To improve the number of overlapping stations, we have incorporated the IGS AC solution from MIT. Our implementations have shown that a weekly combined solutions can be carried out either with CATREF or GLOBK and confirm that the two independent packages agree to within $\pm 1 \mathrm{~mm}$. However, in terms of computation time, GLOBK outperforms CATREF. A combined solution can provide results for a larger number of stations in a single consistent reference frame than any of the individual TACs may be able to. This holds true even for stations contributed by a single TAC but at a loss of reliability. As more TAC solutions become available, the TIGA combinations will also able to identify any inconsistencies between different individual solutions as evidenced from the well established IGS combination. This would deliver the full potential of a TIGA combination, i.e. to provide time series of vertical land movements at or close to tide gauges for sea level studies in a well defined global reference frame.

Acknowledgements The computational resources used in this study were provided by the High Performance Computing Facility at the University of Luxembourg, Luxembourg. The IGS and its ACs are highly appreciated for their data, products and solutions. We are especially thankful to the TIGA data providers and the SONEL archive, and acknowledge the contributions from three anonymous reviewers.

\section{References}

Altamimi Z, Sillard P, Boucher C (2002) A new release of International Terrestrial Reference Frame for Earth science applications. J Geophys Res 107(B10):2214, doi10.1029/2001JB000561
Blewitt (1989) Carrier phase ambiguity resolution for the global positioning system applied to geodetic baselines up to $2000 \mathrm{~km}$. J Geophys Res 94(B8):10,187-10,203, doi10.1029/JB094iB08p10187

Dach R, Hugentobler U, Fridez P, Meindl M (2007) Bernese GPS Software Version 5.0. Tech. rep., Astronomical Institute, University of Bern, Switzerland

Dong D, Herring T, King R (1998) Estimating regional deformation from a combination of space and terrestrial geodetic data. J Geod 72:200-214, doi10.1007/s001900050161

Fu Y, Freymueller J, van Dam T (2012) The effect of using inconsistent ocean tidal loading models on GPS coordinate solutions. J Geod 86:409-421, doi10.1007/s00190011-0528-1

Ge M, Gendt G, Rothacher M, Shi C, Liu J (2008) Resolution of Gps carrier-phase ambiguities in Precise Point Positioning (PPP) with daily observations. J Geod 82:389399, doi10.1007/s00190-007-0187-4

Herring T, King R (2006) GLOBK Reference Manual: Global Kalman filer VLBI and GPS analysis program release 10.3. Tech. rep., Dep. of Earth., Atmos., and Planet. Sci., Mass. Inst. of Technol., Cambridge.

Petit G, Luzum B (2010) IERS Technical Note no 36., IERS Convention Centre. Tech. rep., Frankfurt am Main: Verlag des Bundesamts für Kartographie und Geodäsie

Rebischung P (2012) IGb08: an update on IGS08. http://igscb.jpl.nasa.gov/pipermail/igsmail/2012/006655.html

Rudenko S, Schön N, Uhlemann M, Gendt G (2013) Reprocessed height time series for GPS stations. Solid Earth 4:2341, doi10.519/se-4-23-2013

Schöne T, Schön N, Thaller D (2009) IGS Tide Gauge Benchmark Monitoring Pilot Project (TIGA): Scientific benefits. J Geod 83:249-261, doi10.1007/s00190-0080269-y

Steigenberger T, Rothacher M, Dietrich R, Fritsche M, Rülke A, Vey S (2006) Reprocessing of a global GPS network. J Geophys Res 111(B05):200-214, doi10.1029/2005JB003747

Teferle F, RM B, Williams S, Baker T, Dodson A (2006) Using continuous GPS and absolute gravity to separate vertical land movements and changes in sea level at tide gauges in the UK. Phil Trans Roy Soc 364:917-930, doi10.1098/rsta.2006.1746

Wöppelmann G, Martín Míguez B, Bouin M, Altamimi Z (2007) Geocentric sea-level trend estimates from GPS analyses at relevant tide gauges world-wide. Global and Planetary Change 57:396-406, doi10.1016/j.gloplacha.2007.02.002

Wöppelmann G, Letetrel C, Santamaria-Gómez A, Bouin M, Collilieux X, Altamimi Z, Williams S, Martín Míguez B (2009) Rates of sea-level change over the past century in a geocentric reference frame. Geophys Res Lett 36 